\title{
A simple model for the influence of push-morainal banks on the calving and stability of glacial tidewater termini
}

\author{
Mark P. Fischer, Ross D. Powell \\ Department of Geology, Northern Illinois University, De Kalb, Illinois 60115-2854, U.S.A.
}

\begin{abstract}
Push-morainal banks at the grounding lines of tidewater termini of temperate glaciers are the source of two types of restraining forces operating at the glacier terminus. Horizontal normal forces derive from the lateral support and transport of the bank of sediment at the terminus, whereas a horizontal shear force operates along the base of a bank pushed in front of an advancing glacier. The simple model we present suggests that bank-related restraining forces are significantly larger than the restraining force derived from the hydrostatic pressure of water adjacent to the submerged terminus of a glacier. During glacier advance, restraining forces continually increase, resulting in decreasing flow rates, glacier thickening and the eventual cessation of advance. During retreat, restraining forces continually decrease, resulting in increasing flow rates, glacier thinning and the potential for unstable, rapid, sustained retreat. The normal, seasonal, oscillatory advance-retreat cycle of a glacier is moderated by restraining forces associated with push moraines. Unstable retreat is likely initiated when bank-related restraining forces fall below some threshold value during the seasonal retreat cycle. Calving is not a primary cause of glacier retreat, but is more likely a short-term response to increased flow rates. Increased flow rates result in glacier thinning and an approach toward buoyancy, both of which fluctuate seasonally in accordance with bank-related restraining forces.
\end{abstract}

\section{INTRODUCTION}

Calving of glacier cliffs at tidewater termini is the major ablation process, in some cases leading to sustained, rapid retreat and possibly catastrophic collapse of a glacier. In the simplest sense, calving represents the primary negative component of the ice flux at a glacier terminus. The relative rates of calving and ice flow, the primary positive component of terminus ice flux, essentially control the advance and retreat of the ice front. In contrast to ice velocity, however, which can be measured directly on a number of timescales, calving rate is a calculated rather than measured parameter. Determining the factors controlling calving is consequently reduced to a statistical correlation exercise (e.g. Brown and others, 1982).

In the past two decades a significant amount of observational data has been collected to constrain ice flux of the terminus (e.g. Brown and others, 1982; Krimmel and Vaughn, 1987; Meier and Post, 1987; Meier and others, 1994). The most complete dataset comes from Columbia Glacier, Alaska, and demonstrates that flow of tidewater glaciers responds to both short- and long-term forcing from a variety of sources. Rain and wind can cause increases in ice-flow velocity for periods of hours to days, and tidal fluctuations in water depth result in systematic, daily variations in glacier velocity.

Brown and others' (1982) statistical analysis of Columbia Glacier data showed a strong linear correlation between calving rate and water depth at the glacier terminus. Despite the good correlation, however, a physical basis for this relationship was lacking until Hughes (1992) presented a theoretical calving model that not only yielded a linear relation between water depth and calving rate, but also suggested additional calving-rate dependencies on ice buoyancy and crevasse spacing. Van der Veen (1996) called these relationships into question and demonstrated equally strong correlations between the 2 year running-mean calving rate, mean ice thickness, longitudinal stretching rate and the 2 year running-mean ice speed. Van der Veen (1996) further suggested that a universally applicable calving relation may not exist, and that different calving relations may hold for glaciers with stable vs retreating termini. In the well-documented retreat from the Little Ice Age maximum in Glacier Bay, Alaska, a relationship has been found between average rate of terminus retreat and calving rate. However, the relationship does not hold over short periods (Powell, 1983) and is not necessarily related to water depth; and other glaciological factors such as down-wasting, fast flow (e.g. Meier and others, 1985a) and relict crevassing (Powell, 1988) may also be important factors.

\section{Forcing, response and stability}

Krimmel and Vaughn (1987) demonstrated that short-term velocity forcings, coupled with seasonal climate changes and calving responses, result in cyclic, small-amplitude $(\sim 0.5 \mathrm{~km})$ variations in terminus position, with maximum glacier lengths occurring in late spring, and minimum lengths in late fall. This oscillatory effect produces small push-banks on the ice-contact slope of a larger morainal bank (Seramur and others, 1997). Despite these variations, however, the Columbia Glacier terminus maintained an oscillatory "steady state" position until 1984, when it began a sustained, rapid retreat that continues today (Meier and others, 1985a; Van der Veen, 1996). The onset of rapid retreat 
represents an instability in the normal oscillatory cycle of terminus position, and is the subject of this paper.

As noted by Van der Veen (1996), sustained, rapid retreat of Columbia Glacier commenced only after the glacier began retreating off the terminal morainal bank during the normal oscillatory cycle in the summer of 1984 (Meier and others, 1985b). This coincidence suggests a causative relation between retreat from the bank and the onset of rapid retreat. We examine the role of morainal banks in moderating such long-term, unstable responses, through an analysis of the balance of forces at the terminus of a tidewater terminus grounded at a morainal bank. Our intent is to define the restraining forces associated with morainal banks and compare them with other, well-established sources of restraining force (e.g. hydrostatic pressure).

\section{BOUNDARY CONDITIONS AT THE TERMINUS}

The model we invoke follows that suggested by Post (1975), Meier and Post (1987), Mayo (1988) and Alley (1991). In this model, a glacier builds a morainal bank at the terminus while in a retreat position. During advance, the glacier pushes the bank ahead of it, with bank size continually increasing due to the addition of sediments. Figure 1 shows a generalized longitudinal cross-section through a grounded glacier and the tidewater terminus with an associated push-morainal bank. In our model, sediment is continually added to the bank from supraglacial, englacial and subglacial sources, with a minor additional component provided by scraping-off at the morainal toe (e.g. Hunter and others, 1996a). Sedimentation rates increase exponentially toward the terminus, tending to maintain the overall wedge shape of the morainal bank (Cowan and Powell, 1991). Sediment is removed from the bank when the glacier overrides its push-morainal bank. Submarine slumping and mass wasting redistribute sediment in the forebank area, but are not significant mechanisms for sediment removal.

The geometry of glacier termini against the backs of morainal banks appears to vary in known cases. Examples in Alaska at present termini (Powell, 1991; Hunter and others, 1996a) and from seismic reflection records of recently abandoned banks (Seramur and others, 1997; Cai and others, 1997), as well as those from Pleistocene morainal bank exposures (e.g. Hunter and others, 1996b), appear to show a range in geometries from a steep, near-vertical face to a ramp-type form. In some cases there even appear to be buried ice bodies in the bank. However, the variability in form is not well documented, and causes of the variability are not yet understood. In this first attempt, we take the simplest case for an idealized model, that of a vertical contact between glacial ice and the morainal bank. This represents an end-member category and provides for the maximum back-stress case of the bank on the glacier. As bank backs become more ramp-like, the back-stress effect should decrease, and those cases require further modeling. Using the simplest geometry for the ice-bank interface, we note that depending on the relative motion of the ice front over time, three general sets of boundary conditions are possible at the glacier terminus.

\section{Advancing glacier}

An advancing glacier actively pushes a bank of sediment in front of it, analogous to the pile of sediment pushed in front of a bulldozer. When comprised of uniform, non-cohesive materials, the sediment bank will uniformly taper away from the terminus in the bank-front section as shown in the idealized model in Figure 2. As discussed by Davis and others (1983) and Dahlen (1984), such "critically tapered wedges" assume a taper determined by several factors, including the frictional characteristics of the constituent particles and the sliding conditions at the base of the wedge. For our model, the actual dimensions of the bank-front wedge are also important, as the proportions of the wedge will be related to the volume of sediment in the whole bank. As sediment accumulates at the terminus, the morainal bank will grow self-similarly (e.g. Turcotte, 1992) at a constant taper (Davis and others, 1983). Although the type and facies distribution of sediments in the wedge may be significant in determining the geometry of the bank-front wedge, we simplistically treat the bank as a uniform mass of noncohesive sediment.

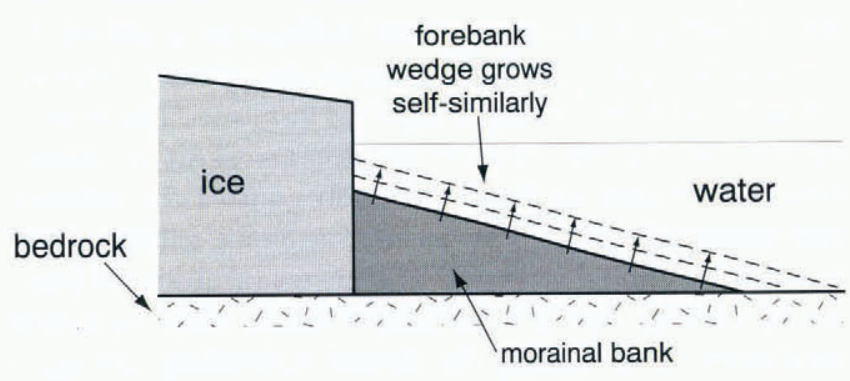

Fig. 2. Idealized model of a grounded tidewater terminus during a prolonged phase of glacier advance.

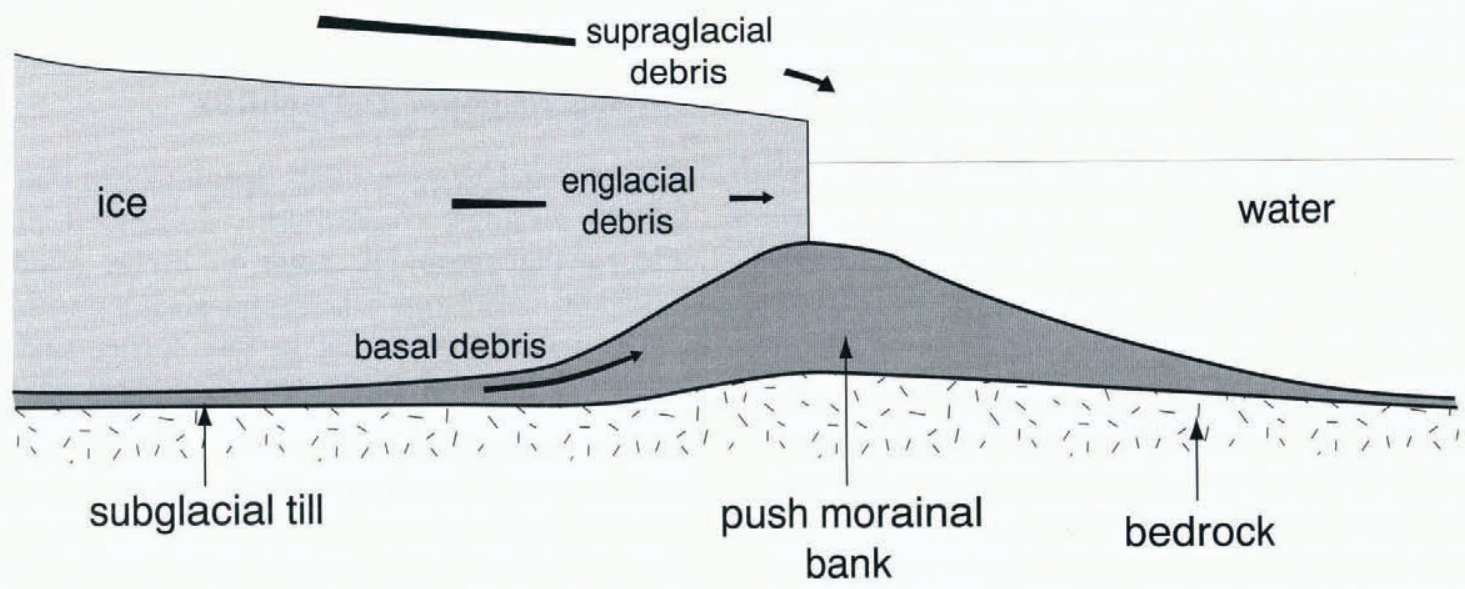

Fig. 1. Schematic diagram of the natural, physical system at the grounded tidewater terminus of a temperate glacier. 


\section{Retreating glacier}

A retreating glacier creates a gap between the cliff and the bank crest. During retreat, the bank may assume different geometries depending on the relative rates of retreat and sedimentation (Fig. 3). If sedimentation cannot keep pace with retreat, the glacier may retreat completely from the bank, leaving an asymmetric form with a gentle foreslope and a backslope near the angle of repose (Fig. 3c). Observations of morainal bank geometry suggest this may be the most common case (Powell, 1991; Hunter and others, 1996a).

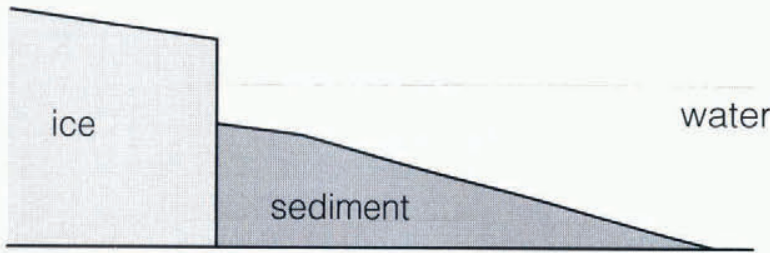

sedimentation outpaces retreat

b

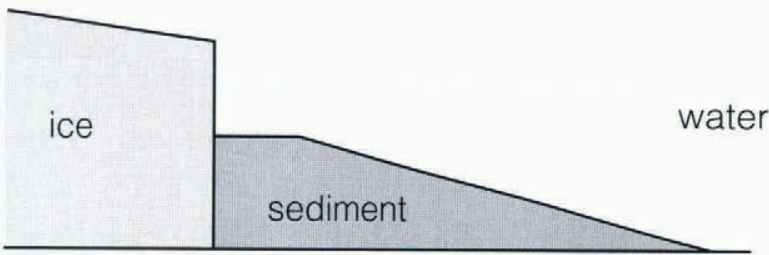

sedimentation keeps pace with retreat

c

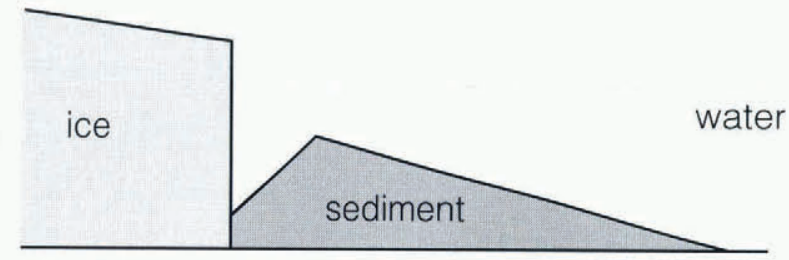

sedimentation does not keep pace with retreat

Fig. 3. Idealized models of morainal bank geometry during prolonged glacier retreat.

\section{Stationary glacier}

A possible, transient case of an unmoving terminus in steady state must also be considered. In this case the morainal bank is stationary, and sediment accumulating at the glacier terminus steepens the foreslope of the sediment wedge. If the terminus is stationary long enough, the bank foreslope will steepen to the angle of repose of the constituent material, and thereafter the wedge will grow self-similarly.

\section{TERMINUS RESTRAINING FORGES}

Our analysis considers only the forces at the glacier terminus that resist flow of the glacier. We use the simple model in Figures 4 and 5 to formulate the problem, and discuss three principal restraining forces (see Appendix for symbols used): a horizontal normal force due to the water $\left(F_{\mathrm{W}}\right)$, a horizontal normal force due to the morainal bank $\left(F_{\mathrm{M}}\right)$, and a horizontal shear force associated with frictional sliding along the base of the forebank wedge $\left(F_{\mathrm{BS}}\right)$. Because different combinations of restraining forces operate under each set of boundary conditions, we first discuss the forces common to all sets of boundary conditions, and then discuss restraining forces associated with specific cases. We do not

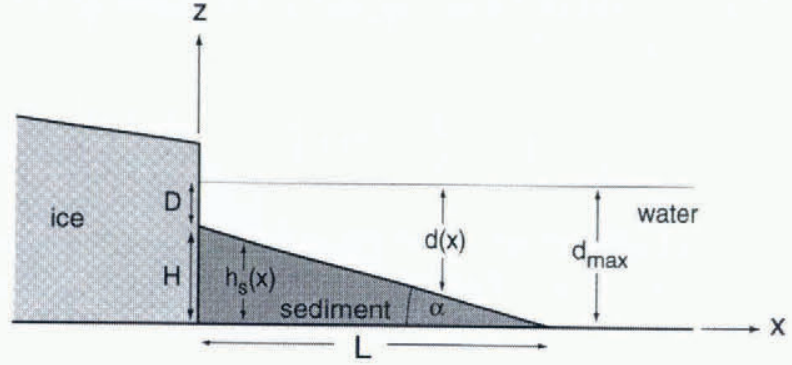

Fig. 4. Geometry, coordinate system and important parameters in the model. Coordinate system is anchored to the toe of the glacier and moves with it during advance or retreat.

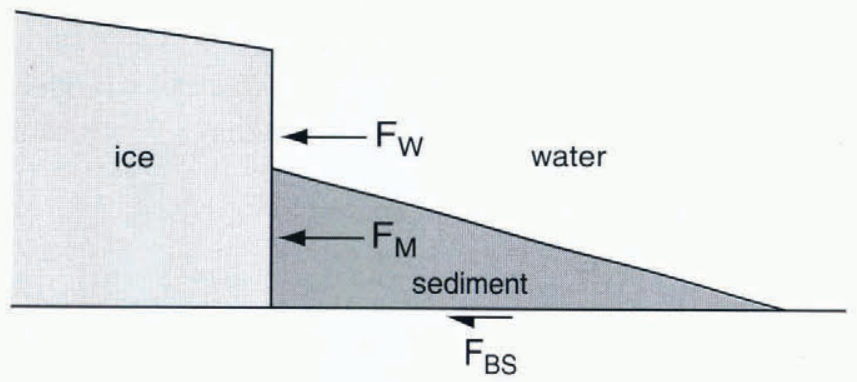

Fig. 5. Restraining forces associated with grounding-line push-morainal banks.

discuss the forces associated with long-term stationary termini, as these conditions are potentially rare. In all cases, we assume the morainal bank sediments are saturated with water at hydrostatic pressure.

\section{Hydrostatic pressure}

The hydrostatic fluid pressure $\left(P_{\mathrm{f}}\right)$ at any vertical position in the system is given by

$$
P_{\mathrm{f}}(z)=\rho_{\mathrm{w}} g\left(d_{\max }-z\right),
$$

where $\rho_{\mathrm{w}}$ is the density of the water, $g$ is the acceleration of gravity, $d_{\max }$ is the water depth beyond the bank foreslope, and the equation is valid for all $z \leq d_{\max }$. At the vertical ice-water interface, where the water depth is $D$, the hydrostatic restraining force $\left(F_{\mathrm{W}}\right)$ per unit width at the glacier terminus is given by

$$
F_{\mathrm{W}}=\frac{1}{2} \rho_{\mathrm{w}} g D^{2} .
$$

This hydrostatic restraining force is operative during all stages of glacier advance and retreat, as long as the bank remains submerged.

\section{Shear force from basal sliding}

As a glacier advances it pushes a bank of sediment in front of it. As the forebank wedge is transported, it overrides finergrained, more distal sediments on the sea floor. Some of these sediments are scraped from the sea floor and accreted to the toe or underside of the sedimentary forebank wedge. Those sediments not accreted serve as a weak detachment layer beneath the forebank wedge. Evidence of such detachment layers, including high vertical-strain gradients and the presence of narrow, subhorizontal shear zones, is seen in many subareally developed push moraines (e.g. Van der Wateren, 1986, 1994). Any time a push moraine advances, a shear force related to basal sliding of the moraine operates to resist glacier flow. 
The basal sliding shear force per unit width of the morainal bank is given by

$$
F_{\mathrm{BS}}=\int_{0}^{L} \tau_{\mathrm{b}}(x) \mathrm{d} x,
$$

where $\tau_{\mathrm{b}}(x)$ is the distribution of shear stress along the base of a sediment wedge of horizontal length $L$ (Fig. 4). For a uniform, non-cohesive wedge of sediment,

$$
\tau_{\mathrm{b}}(x)=\mu_{\mathrm{b}} \sigma_{z z}{ }^{\prime}(x, z=0),
$$

where $\mu_{\mathrm{b}}$ is the coefficient of internal friction (Jaeger and Cook, 1979) of the sediments comprising the basal detachment layer, and $\sigma_{z z}{ }^{\prime}(x, z=0)$ is the distribution of normal effective stress along the base of the forebank wedge. To fully describe $F_{\mathrm{BS}}$, we must explicitly know this normal stress distribution along the base of the wedge, a quantity we now derive.

From the schematic vertical stress profile in Figure 6, it is clear that the total vertical stress at any point in the bank consists of two components. Consequently, vertical effective stress at any point in the bank can be written as

$$
\sigma_{z z}{ }^{\prime}(x, z)=\left[\sigma_{z z}{ }^{\mathrm{w}}(x)+\sigma_{z z}{ }^{\mathrm{s}}(x, z)\right]-P_{\mathrm{f}}(z) .
$$

Seeing from Figure 4 that the upper surface of the forebank wedge is defined by

$$
h_{\mathrm{s}}(x)=(L-x) \tan \alpha,
$$

the distribution of vertical stress along the top of the bank is $\sigma_{z z}{ }^{\mathrm{w}}(x)=\rho_{\mathrm{w}} g\left[d_{\max }-h_{s}(x)\right]=\rho_{\mathrm{w}} g\left[d_{\max }-(L-x) \tan \alpha\right]$,

and anywhere in the wedge, the vertical stress due only to the weight of the sediment is

$$
\sigma_{z z}{ }^{\mathrm{s}}(x, z)=\rho_{\mathrm{s}} g\left[h_{\mathrm{s}}(x)-z\right]=\rho_{\mathrm{s}} g[(L-x) \tan \alpha-z],
$$

where $\rho_{\mathrm{s}}$ is the mean density of the sediments in the bank. Substituting Equations (1), (7) and (8) into Equation (5)
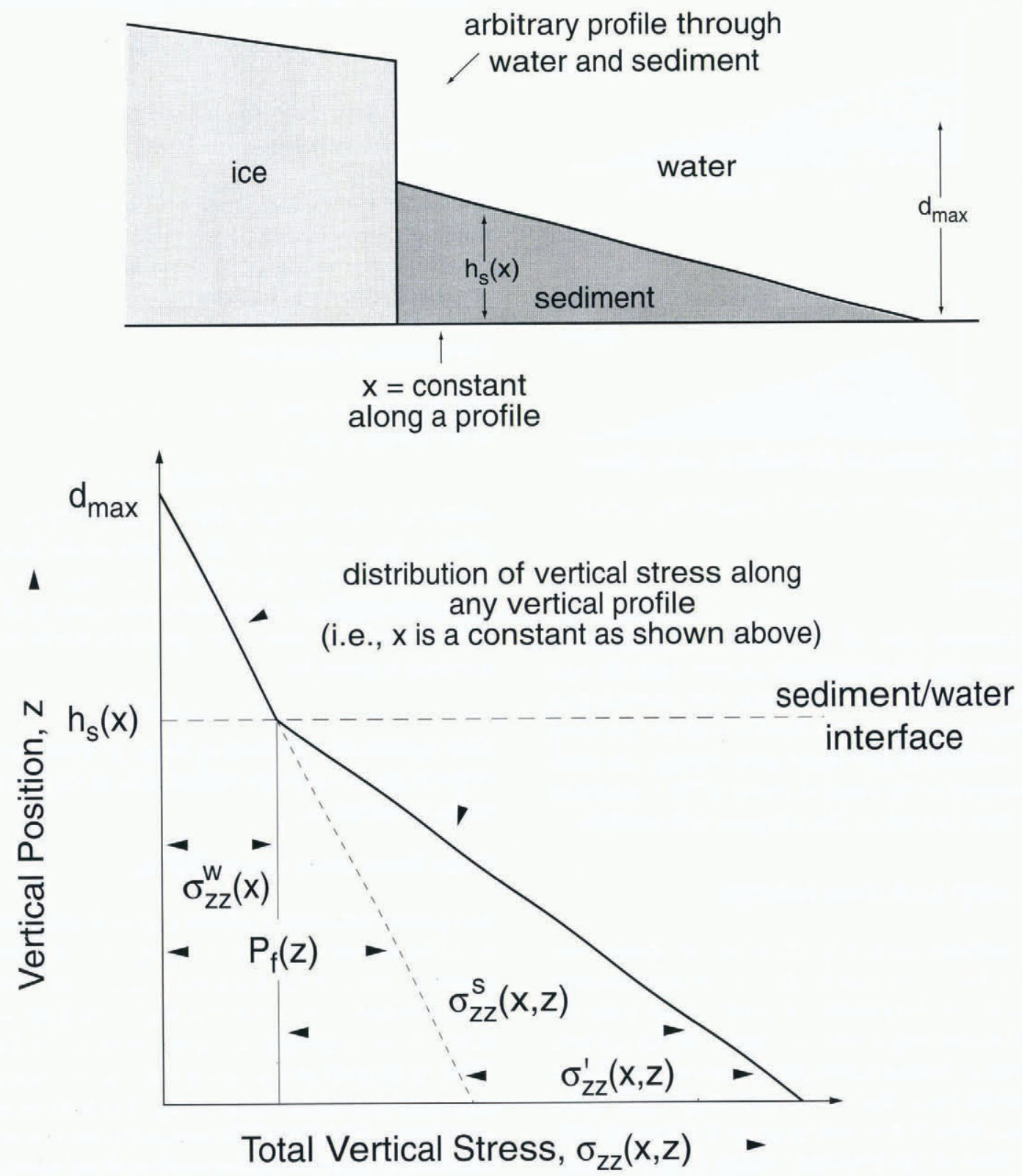

Fig. 6. Variation of total vertical stress $\left(\sigma_{z z}\right)$ along any vertical profile (i.e. $x$ is constant) through the morainal bank. Total vertical stress at any point in the forebank sediment wedge is the sum of the weight of the water column acting on top of the wedge $\left(\sigma_{z z} \mathrm{w}(x)\right)$, plus the weight of the sediment column $\left(\sigma_{z z}{ }^{\mathrm{s}}(x, z)\right)$ above the point in question. 
yields the equation for vertical effective stress anywhere in the bank:

$$
\begin{aligned}
\sigma_{z z}{ }^{\prime}(x, z)= & \rho_{\mathrm{w}} g\left[d_{\max }-(L-x) \tan \alpha\right] \\
& +\rho_{\mathrm{s}} g[(L-x) \tan \alpha-z]-\rho_{\mathrm{w}} g\left(d_{\max }-z\right) .
\end{aligned}
$$

Substituting $z=0$, simplifying and rearranging yields the equation for vertical effective stress at the base of the morainal bank,

$$
\sigma_{z z}{ }^{\prime}(x, z=0)=\left(\rho_{\mathrm{s}}-\rho_{\mathrm{w}}\right) g(L-x) \tan \alpha .
$$

The shear force acting along the base of the bank is now found by substituting Equation (10) into Equations (4) and (3), and evaluating the integral to obtain:

$$
\begin{aligned}
F_{\mathrm{BS}} & =\int_{0}^{L} \mu_{\mathrm{b}}\left[\left(\rho_{\mathrm{s}}-\rho_{\mathrm{w}}\right) g(L-x) \tan \alpha\right] \mathrm{d} x \\
& =\frac{1}{2} L^{2} \mu_{\mathrm{b}} g\left(\rho_{\mathrm{s}}-\rho_{\mathrm{w}}\right) \tan \alpha .
\end{aligned}
$$

\section{Horizontal normal force during advance}

Davis and others (1983) demonstrated that a non-cohesive mass of material will naturally assume a prismatic wedge geometry when pushed by a rigid boundary. Similar conclusions were drawn by Elliott (1976) and Chapple (1978) for cohesive, ductile materials. Although derived to describe the geometry and mechanics of thin-skinned fold and thrust belts and accretionary prisms along subducting plate boundaries, these "critical wedge" models are also applicable to moraines pushed before an advancing glacier (e.g. Van der Wateren, 1994). The following relies extensively on the work of Davis and others (1983) and Dahlen (1984), to which the reader is referred for details of non-cohesive critical-wedge mechanics.

According to Davis and others (1983), a "critically tapered" wedge is the "thinnest body that can be thrust over its basal décollement without any internal deformation". When new material is added to a forebank wedge, by either sedimentation, underplating or accretion at the toe, the wedge "deforms internally while sliding in order to accommodate the influx and to maintain its critical taper" (Davis and others, 1983). The sediment in the morainal bank is therefore considered to be in a "critical state", because it is continually in a state of failure everywhere internally and along the base.

The critical state of stress in a bank composed of uniform, cohesionless material is illustrated by the Mohr circle in Figure 7. Shear and normal effective stress along the wedge base are given respectively by $\tau_{\mathrm{b}}(x)$ and $\sigma_{z z}{ }^{\prime}(x, z=0)$. These two stresses are related by the criterion for frictional sliding along the wedge base: a linear Coulomb shear failure envelope with slope $\tan \left(\phi_{b}\right)=\mu_{\mathrm{b}}$, where $\mu_{\mathrm{b}}$ is the coefficient of friction along the base of the forebank wedge. Shear and normal effective stresses along failure planes in the wedge interior, $\tau_{\mathrm{i}}(x)$ and $\sigma_{\mathrm{ni}}{ }^{\prime}(x, z)$, are related by a second linear Coulomb shear failure criterion with slope $\tan \left(\phi_{\mathrm{i}}\right)=\mu_{\mathrm{i}}$, where $\mu_{\mathrm{i}}$ is the coefficient of friction of sediment comprising the wedge.

Because of frictional sliding along the wedge base, principal stress orientations in the forebank wedge are inclined at an angle $\psi$ to the $x-z$ coordinate system describing the wedge (Fig. 8). For uniform, cohesionless materials, this misorientation angle is constant throughout the wedge (Dahlen, 1984), and is related to the wedge taper, material

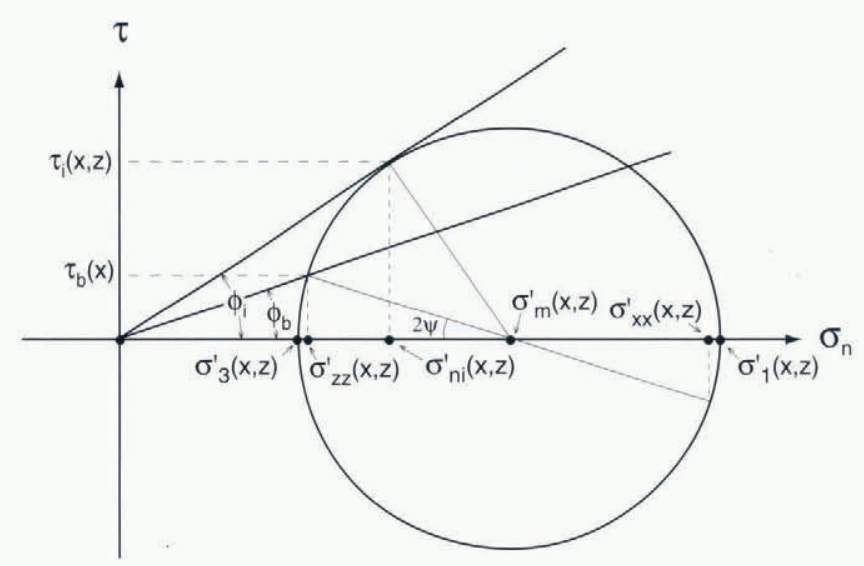

Fig. 7. State of effective normal and shear stress in an actively advancing, critically tapered forebank wedge of uniform, cohesionless sediment. After Davis and others (1983).

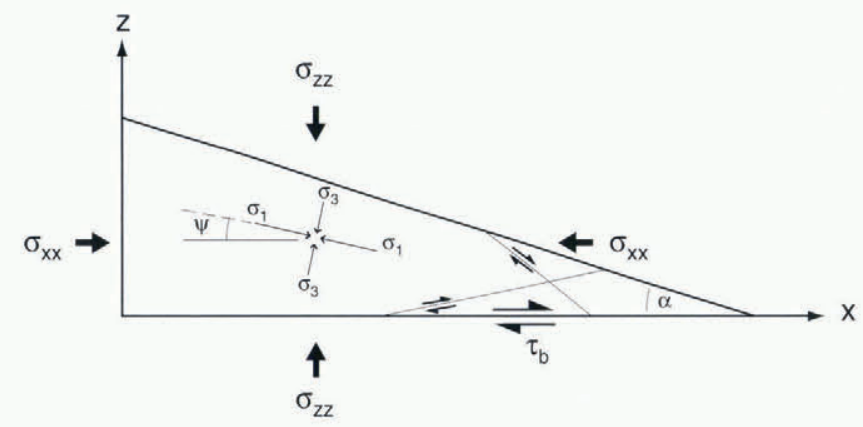

Fig. 8. Geometry of stresses in a critically tapered forebank wedge of sediment. Principal stresses are inclined at an angle $\psi$ to the wedge base because of frictional sliding. For the simple case of a planar, horizontal base, wedge taper is defined by the angle $\alpha$.

density and fluid pressure ratio in the wedge $\left(\lambda=P_{\mathrm{f}} / \sigma_{z z}\right.$; Hubbert and Rubey, 1959) by

$$
\psi=\frac{1}{2} \arcsin \left(\frac{\sin \alpha^{\prime}}{\sin \phi_{i}}\right)-\frac{1}{2} \alpha^{\prime},
$$

where $\alpha^{\prime}$ is Dahlen's (1984) "modified slope angle" defined by

$$
\alpha^{\prime}=\arctan \left\{\left[\frac{1-\left(\frac{\rho_{\mathrm{w}}}{\rho_{\mathrm{s}}}\right)}{1-\lambda}\right] \tan \alpha\right\},
$$

and $\alpha$ is the forebank wedge taper as shown in Figure 4. The graph in Figure 9 illustrates the relation between sediment density and $\alpha^{\prime}$ for wedge tapers of $15^{\circ}$ and $20^{\circ}$, the typical upper and lower bounds to morainal bank foreslope angles measured by Hunter (1994) for three Alaskan glaciers. Figure 10 illustrates the relation between $\psi$ and $\phi_{\mathrm{i}}$ for various sediment densities and critical taper angles of $15^{\circ}$ and $20^{\circ}$.

In the following analysis, we assume a sediment density of $2.2 \mathrm{~g} \mathrm{~cm}^{-3}$, a wedge taper of $15^{\circ}$, hydrostatic fluid pressure $(\lambda=0.465)$, internal friction angle of $40^{\circ}$ and a water density of $1 \mathrm{~g} \mathrm{~cm}^{-3}$. In a morainal bank where these assumptions hold, the stress misorientation angle is $\sim 5^{\circ}$ (Fig. 10), and failure within the wedge will be on normal and thrust faults with orientations shown in Figure 8. Although deformation both within the forebank wedge and at the wedge base may be complex, we need only know the distribution of normal stress along the back of the morainal bank in order to deter- 


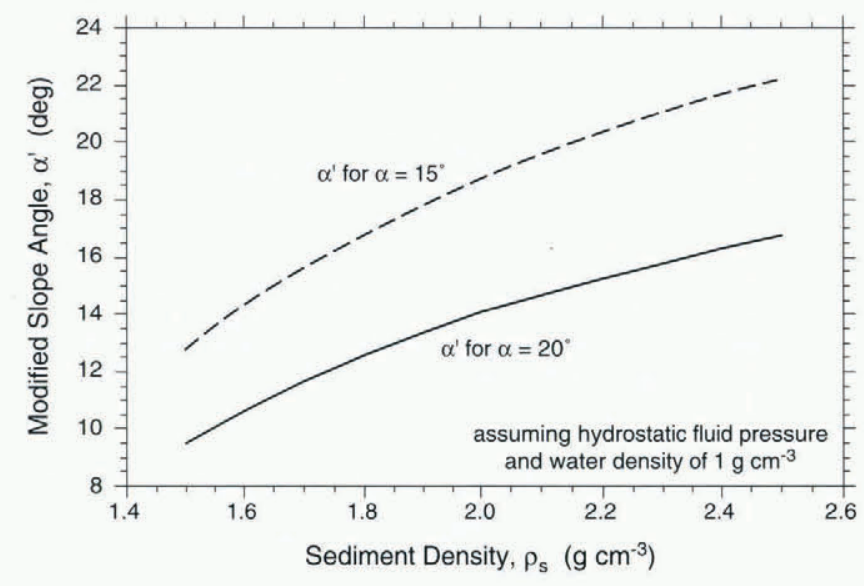

Fig. 9. Variation of modified slope angle as a function of bank sediment density.

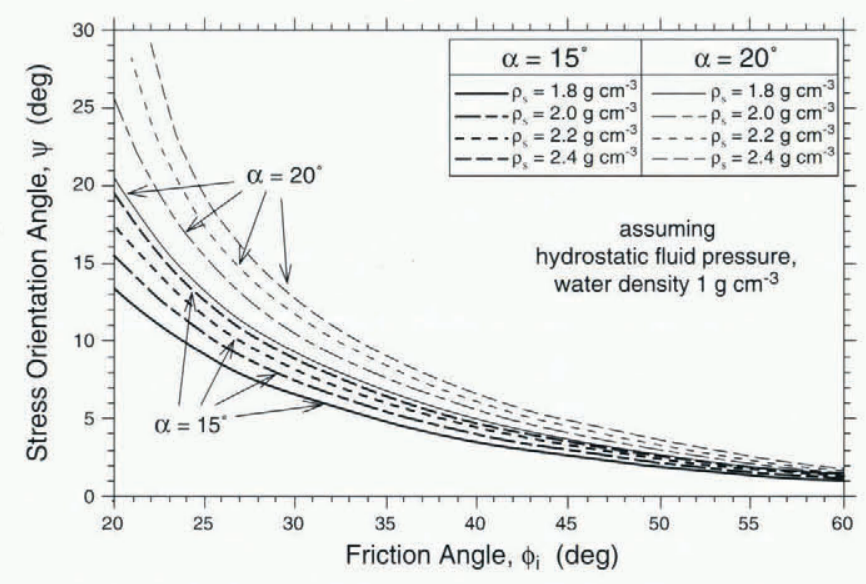

Fig. 10. Variation of stress misorientation angle as a function of friction angle for wedge tapers of $15^{\circ}$ and $20^{\circ}$ and various sediment densities.

mine the horizontal, normal restraining force operating during glacier advance.

To determine the horizontal normal force associated with pushing of the morainal bank, we utilize the Mohr circle in Figure 7, and note that for a critically tapered wedge,

$$
\tan 2 \psi=\frac{\tau_{\mathrm{b}}(x)}{\frac{\sigma_{x x}{ }^{\prime}(x, z)-\sigma_{z z}{ }^{\prime}(x, z)}{2}} .
$$

After expanding the horizontal effective stress and rearranging, we find that total horizontal stress at any position within the bank is given by

$$
\sigma_{x x}(x, z)=\frac{2 \tau_{\mathrm{b}}(x)}{\tan 2 \psi}+\sigma_{z z}{ }^{\prime}(x, z)+P_{\mathrm{f}}(z) .
$$

The horizontal normal force per unit width along the back of an advancing, critically tapered forebank wedge (Fig. 4) is therefore found from

$$
F_{\mathrm{Ma}}=\int_{0}^{H} \sigma_{x x}(x=0, z) \mathrm{d} z,
$$

where $\sigma_{x x}(x, z)$ is given by Equation (15).

Setting $x=0$ and substituting Equations (1), (4) and (9) into Equation (16), we arrive at a complete expression for the horizontal normal force per unit width of the morainal bank during glacier advance:

$$
\begin{aligned}
F_{\mathrm{Ma}}= & \int_{0}^{H}\left\{\left[\frac{2\left[\mu_{\mathrm{b}}\left(\rho_{\mathrm{s}}-\rho_{\mathrm{w}}\right) g L \tan \alpha\right]}{\tan 2 \psi}\right]\right. \\
+ & {\left[\rho_{\mathrm{w}} g\left(d_{\max }-L \tan \alpha\right)+\rho_{\mathrm{s}} g(L \tan \alpha-z)\right] } \\
& {\left.\left[-\rho_{\mathrm{w}} g\left(d_{\max }-z\right)\right]+\rho_{\mathrm{w}} g\left(d_{\max }-z\right)\right\} \mathrm{d} z . }
\end{aligned}
$$

Simplifying, rearranging, and evaluating this integral yields:

$$
\begin{aligned}
F_{\mathrm{Ma}}= & \left\{\frac{2\left[\mu_{\mathrm{b}}\left(\rho_{\mathrm{s}}-\rho_{\mathrm{w}}\right) g L \tan \alpha\right]}{\tan 2 \psi}\right\} H \\
& +\left[\rho_{\mathrm{w}} g\left(d_{\max }-L \tan \alpha\right) H\right. \\
& \left.+\rho_{\mathrm{s}} g\left(H L \tan \alpha-\frac{1}{2} \mathrm{H}^{2}\right)\right] .
\end{aligned}
$$

\section{Horizontal normal force during retreat}

When a glacier retreats, only one bank-related restraining force acts at the glacier terminus. This restraining force is a horizontal normal force ( $F_{\mathrm{M}}$; Fig. 5) derived from the wall of sediment laterally supported by the ice cliff. As noted in Figure 3, a variety of bank geometries can develop as a glacier retreats. The normal force associated with each of these geometries is intimately associated with the distribution of horizontal total stress along the ice-sediment interface, such that the horizontal force per unit width of the glacier terminus is given by Equation (16), where $\sigma_{x x}(x=0, z)$ is now a new function, yet to be determined.

Because a full analysis of the horizontal stress distribution associated with each of the wide array of possible bank geometries is beyond the scope of this paper, we instead present a solution for $\sigma_{x x}(x=0, z)$ when sedimentation rate does not keep pace with glacier retreat (Fig. 3c). We examine this case because it represents a minimum bound to the morainal-bank-derived horizontal normal force acting at the terminus of a retreating glacier.

For a non-cohesive material resting at the angle of repose, the ratio of vertical to horizontal effective stresses is controlled by the frictional properties of the material particles such that

$$
\frac{\sigma_{z z}{ }^{\prime}(x, z)}{\sigma_{x x}{ }^{\prime}(x, z)}=\left[\left(\mu^{2}+1\right)^{\frac{1}{2}}+\mu\right]^{2},
$$

where $\mu$ is the coefficient of friction of the material, and is equal to $\tan \phi$ where $\phi$ is the angle of repose of the material (Zoback and Healy, 1984). Substituting $C$ for the constant in brackets in Equation (19) above, expanding the horizontal effective stress term $\sigma_{x x}{ }^{\prime}(x, z)=\sigma_{x x}(x, z)-P_{\mathrm{f}}(z)$ and rearranging, yields an equation for total horizontal stress anywhere in a non-cohesive pile of sediment resting at the angle of repose:

$$
\sigma_{x x}(x, z)=\frac{1}{C} \sigma_{z z}{ }^{\prime}(x, z)+P_{\mathrm{f}}(z) .
$$

Substituting Equations (9) and (1) into Equation (20), and setting $x=0$, we find the distribution of horizontal stress 
along the ice-morainal-bank interface at the glacier terminus, the grounding line, during retreat to be

$$
\begin{aligned}
\sigma_{x x}(x=0, z)= & \frac{1}{C}\left\{\rho_{\mathrm{w}} g\left[d_{\max }-L \tan \alpha\right]\right. \\
& \left.+\rho_{\mathrm{s}} g[L \tan \alpha-z]-\rho_{\mathrm{w}} g\left(d_{\max }-z\right)\right\} \\
& +\rho_{\mathrm{w}} g\left(d_{\max }-z\right) .
\end{aligned}
$$

Because we are now only interested in the height of the bank at the grounding line ( $H$; Fig. 4), which is no longer simply related to the dimensions of the entire morainal bank, we can substitute $H$ for $L \tan \alpha$ to obtain:

$$
\begin{aligned}
\sigma_{x x}(x=0, z)= & \frac{1}{C}\left\{\rho_{\mathrm{w}} g\left[d_{\max }-H\right]+\rho_{\mathrm{s}} g[H-z]\right. \\
& \left.-\rho_{\mathrm{w}} g\left(d_{\max }-z\right)\right\}+\rho_{\mathrm{w}} g\left(d_{\max }-z\right) .
\end{aligned}
$$

The horizontal restraining force per unit width of the glacier terminus during retreat is now found by integrating the horizontal stress distribution derived in Equation (22), and is given by:

$$
\begin{aligned}
F_{\mathrm{Mr}}= & \int_{0}^{H} \sigma_{x x}(x=0, z) \mathrm{d} z=\frac{g H^{2}}{2 C}\left(\rho_{\mathrm{s}}-\rho_{\mathrm{w}}\right) \\
& +\rho_{\mathrm{w}} g H\left(d_{\max }-\frac{1}{2} H\right) .
\end{aligned}
$$

\section{COMPARISON OF RESTRAINING FORCES}

Figure 11 illustrates the behavior of the four restraining forces at glacier termini derived in Equations (2), (11), (18) and (23). Figure 12 illustrates the combined effect of these forces during advance and retreat of a marine-ending glacier with a tidewater terminus. These results suggest that glacial advance is an inherently stable process, where restraining forces continually increase as the morainal bank

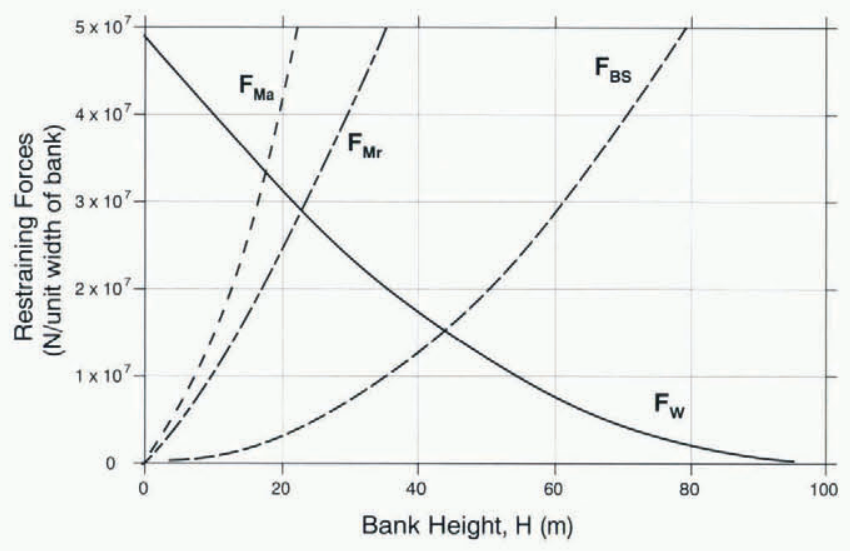

Fig. 11. Restraining forces acting at a tidewater terminus. Plot shows the force per unit width due to the hydrostatic pressure in the water column $\left(F_{\mathrm{W}}\right)$, basal sliding of the bank $\left(F_{\mathrm{BS}}\right)$, normal stress along the bank-ice interface during advance $\left(F_{\mathrm{Ma}}\right)$, and normal stress along the bank-ice interface during retreat $\left(F_{\mathrm{Mr}}\right)$. Note that $F_{\mathrm{W}}$ decreases as a morainal bank builds, while all other restraining forces increase with increasing height of the bank ( $\mathrm{H}$ in Fig. 4). Calculation done for a bank that builds from 0 to $100 \mathrm{~m}$ height in an area where the maximum water depth is $100 \mathrm{~m}$ (i.e. $d_{\max }=100$ ). Basal sliding force calculated for a basal coefficient of friction, $\mu_{\mathrm{b}}=\tan \left(20^{\circ}\right)$, and normal force during retreat calculated for a coefficient of internal friction, $\mu_{\mathrm{i}}=\tan \left(40^{\circ}\right)$.

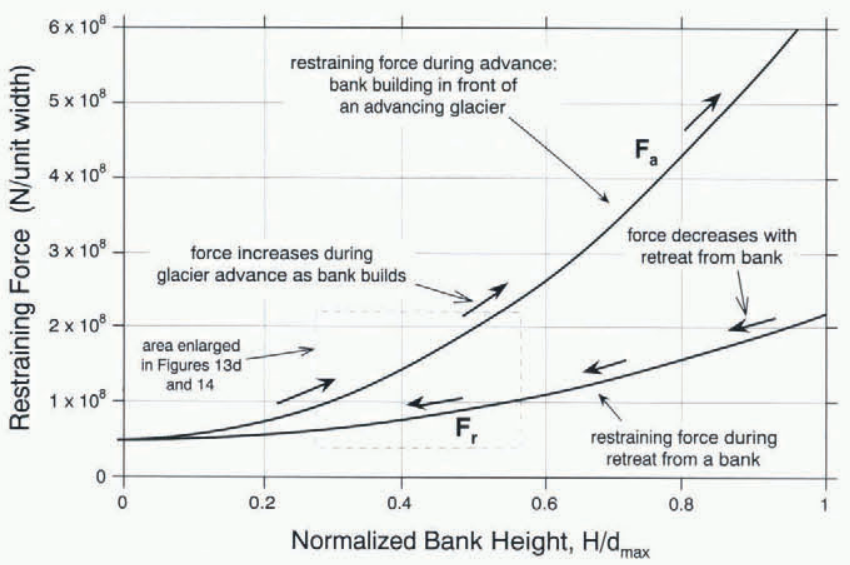

Fig. 12. Restraining forces operating during advance $\left(F_{\mathrm{a}}\right)$ and retreat $\left(F_{\mathrm{r}}\right)$ of a tidewater terminus. Retreat forces are the sum of $F_{\mathrm{W}}$, a decreasing function of morainal bank height at the ice cliff $(H)$, and $F_{\mathrm{Mr}}$, an increasing function of $H$.

builds. Rapid glacier advance is therefore likely to be associated, not with a change in restraining forces at the terminus, but rather with some change in restraining forces developed elsewhere in the system (e.g. the base; Kamb, 1987). In contrast, glacier retreat is an inherently unstable process because terminus restraining forces continually decrease as the glacier retreats from a morainal bank, especially a large terminal bank. By the time the moraine has built to $20-30 \%$ of the maximum water depth, the restraining force associated with water depth at the terminus is relatively insignificant, having been surpassed by horizontal normal forces due to the bank.

Excluding $F_{\mathrm{W}}$, all of the restraining forces are dependent on the material properties of the bank constituent sediments, particularly the coefficient of friction (i.e. angle of repose). Although we do not discuss the effects in detail, we note that decreasing basal friction reduces $F_{\mathrm{BS}}$ and $F_{\mathrm{Mr}}$, whereas decreasing internal friction reduces $F_{\mathrm{Ma}}$. Frictional properties of unconsolidated sediments are at least related to average particle size, uniformity of particle size, particle composition and angularity of particles (Lambe and Whitman, 1969; Dackombe and Gardiner, 1983), suggesting that the restraining forces associated with any specific glacier will be highly dependent on the sedimentological characteristics of a terminal morainal bank. Full analysis of these dependencies will require a sedimentologically accurate and detailed model of facies distribution and evolution in a bank, and is beyond the scope of this paper.

We note that if there is a relationship between calving rate and water depth, this relationship will be most apparent in the absence of other restraining forces at the terminus. When glaciers are grounded along significant morainal banks, the influence of water in restraint at the terminus will be clouded, and may be insignificant compared to other operative forces.

\section{GLACIER ADVANGE, RETREAT AND STABILITY}

This analysis was designed to evaluate whether calving is a cause of glacier retreat (e.g. Brown and others, 1982; Meier and Post, 1987; Meier and others, 1994), or merely an effect of increased glacier flow leading to glacier thinning, and its subsequent approach to buoyancy (e.g. Van der Veen, 1996). The inverse statistical correlation between calving rate and 
water depth at the terminus is presently interpreted in the context of Hughes' (1992) calving model, where calving is driven by bending creep of the glacier terminus, and bending creep is suppressed by greater water depths at the terminus. As noted by Powell $(1983,1988)$ and Van der Veen (1996), however, this interpretation cannot explain the sustained rapid retreat of Alaskan glaciers, which have continued to retreat, despite encountering a variety of water depths at the terminus. Our results suggest why temperate glaciers with grounded tidewater termini may exhibit such rapid retreats.

Seasonal terminus fluctuations have been described for Alaskan tidewater termini for many years, but the bestdocumented has been that of Columbia Glacier. Meier and others (1985b) quantitatively showed that the Columbia Glacier terminus regularly advances between October/November (late autumn/winter) and May/June (spring/early summer) and retreats for the rest of the year. They also showed glacier speed increases synchronously with retreat rate and decreases synchronously with advance rate of the terminus. These regular, small-scale, seasonal fluctuations in glacier motion occur even during the present phase of unstable retreat. Our analysis indicates that bank back-stress may be an important factor in such seasonal terminus fluctuations.

Due partly to the influence of terminus restraining forces (i.e. $F_{\mathrm{Ma}}, F_{\mathrm{M}}, F_{\mathrm{BS}}$; Fig. 4), glacier flow, calving rate and terminus ice flux decrease and increase cyclically, perhaps resulting in, or at least amplifying, seasonal advanceretreat oscillations. Beginning in late winter and continuing through spring, flow velocities are greatest, with the glacier advancing, thinning, and actively building a morainal bank (Fig. 13a). Steepening of the morainal-bank fronts during winter and spring has been attributed to these advances (Hunter and others, 1996a). As the bank builds, restraining forces continually increase (Fig. 13d), which assists in eventually halting net forward motion, and enhancing the onset of glacier thickening behind a large bank through summer and early fall (Fig. 13b). The seasonal glaciological cause of switching this process is not well constrained. However, perhaps a response to previous thinning and an approach toward buoyancy forces an increase in calving, subsequently leading to glacial retreat. By late fall and through early winter, the glacier has retreated partly off the terminal morainal bank (Fig. 13c), restraining forces are at a minimum (Fig. 13d) and a rapid acceleration of flow begins. Because the glacier is now at its thickest yearly average, gravitational driving stresses are large, buoyancy is greatly reduced and calving decreases (Fig. 13c).

The cyclic variation in restraining forces at the terminus has several implications for the three general conditions of long-term glacial movement: advance, retreat and quasistatic. A quasi-static terminus position is possible if shortterm advance and retreat distances are similar. Long-term, steady-state advance occurs if the distance covered by shortterm advance cycles, on average, is greater than the average distance covered by short-term retreat cycles (Fig. 14a). Long-term, steady-state retreat occurs if the distance covered by short-term advance cycles, on average, is less than the average distance covered by short-term retreat cycles. Note that long-term advance is a steady-state, oscillatory process because restraining forces are continually increasing as the glacier advances. Unstable, long-term, rapid advance cannot occur in this situation. This does not apply to surging, however, which is a short-term response to a unique set of conditions wherein ice flux is so high that losses due to calving are overwhelmed. As noted previously, surging behavior is most likely brought about by a change in conditions at the glacier bed, rather than the terminus. Comparatively, although long-term unstable advance is not likely, unstable, long-term retreat is possible, and probably more likely than steady-state retreat, for reasons we now discuss.

Processes which result in glacial retreat, namely, thinning, buoyancy and calving, also result in decreased restraint of the terminus, thereby triggering advance. Therefore, retreat tends to be naturally halted, and steadystate short-term oscillatory behavior is preserved. However, this behavior is possible only in the presence of significant moraine-related restraining forces. These forces not only resist advance, but ultimately induce thickening, reduce buoyancy and therefore inhibit processes that cause retreat. If, during short-term advance, the bank-related restraining forces are not increased to some threshold value (e.g. the bank is not built to some threshold height), the glacier will be initially thinner and more buoyant at the onset of the next short-term retreat cycle. Should this occur, the following seasonal cycle of retreat may reduce restraining forces below some critical level, allowing rapid retreat to begin (Fig. 14b).

This critical level of restraint at the terminus represents a significant instability in the short-term advance-retreat cycle that may be triggered by one or more larger, successive retreat cycles. During such a cycle, the glacier may retreat significantly from the terminal morainal bank, and does not re-establish considerable contact with the bank during the following advance cycle. Unless sedimentation rates are very high, short-term advances behind the terminal morainal bank do not produce mechanically significant morainal banks (i.e. the banks are much smaller), resulting in continually decreasing restraint at the terminus at the onset of each new seasonal advance cycle. In this situation, the glacier never slows and thickens appreciably, and enters a period of rapid, sustained retreat. Because significant restraint at the terminus is not generated during advance behind the terminal morainal bank, steady-state retreat is unlikely.

Although the specifics of individual glacial systems will vary, our analysis generally suggests that quasi-static or steady-state advancing glaciers require restraining forces at the terminus of some threshold magnitude (i.e. terminal morainal banks of some threshold size). We are not presently capable of determining this threshold level of restraining force at the terminus, but note that it will at least be related to bank height, sedimentation rates, sediment types and the evolution of morainal bank geometry. Glaciers with smaller restraint at the terminus will naturally tend toward unstable retreat. Moreover, rapid retreat can be triggered in any system by one or more successive, large, seasonal retreats in which contact with the terminal morainal bank is lost. The cause of such larger short-term retreats is unknown.

\section{GONGLUSIONS}

We have quantified the restraining forces at the tidewater terminus of a temperate glacier building a bank of sediment at the grounding line. Restraining horizontal normal forces 
a

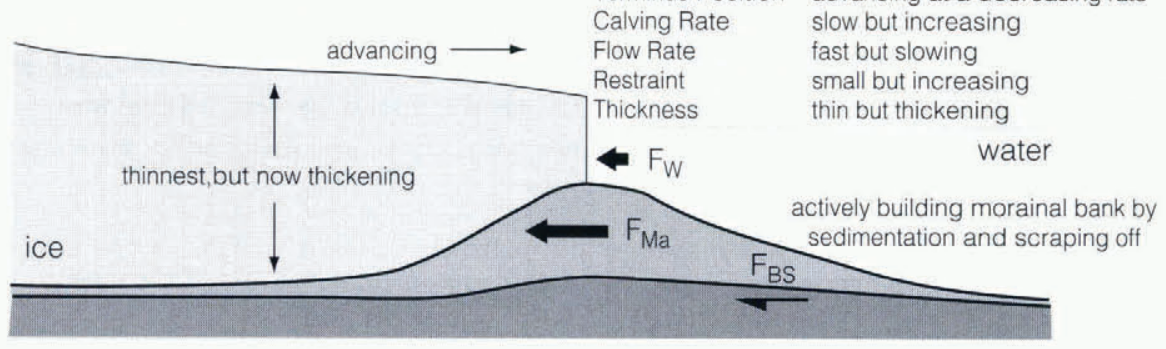

Late Winter through Spring (January-May) b

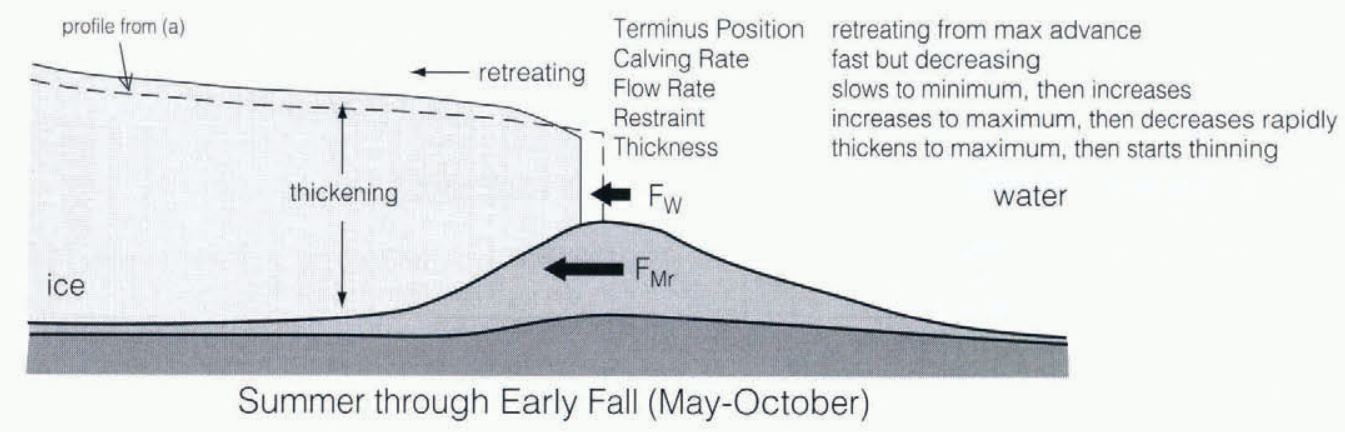

c

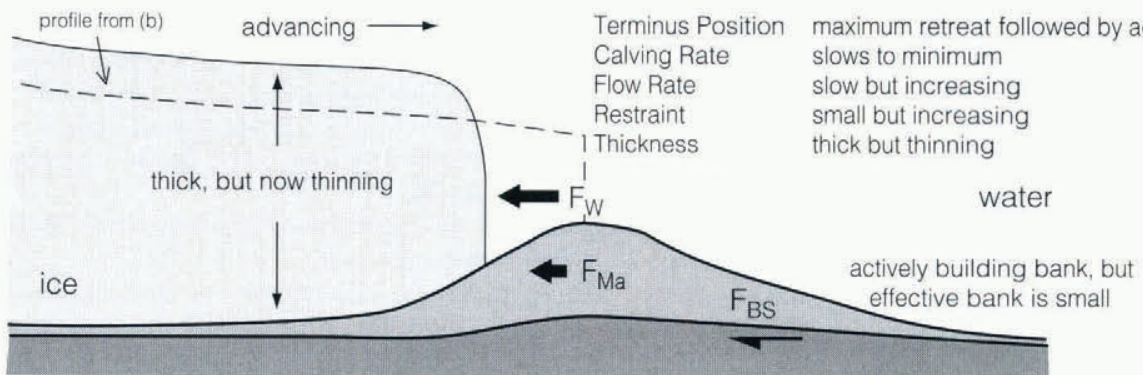

Late Fall through Early Winter (October-January)

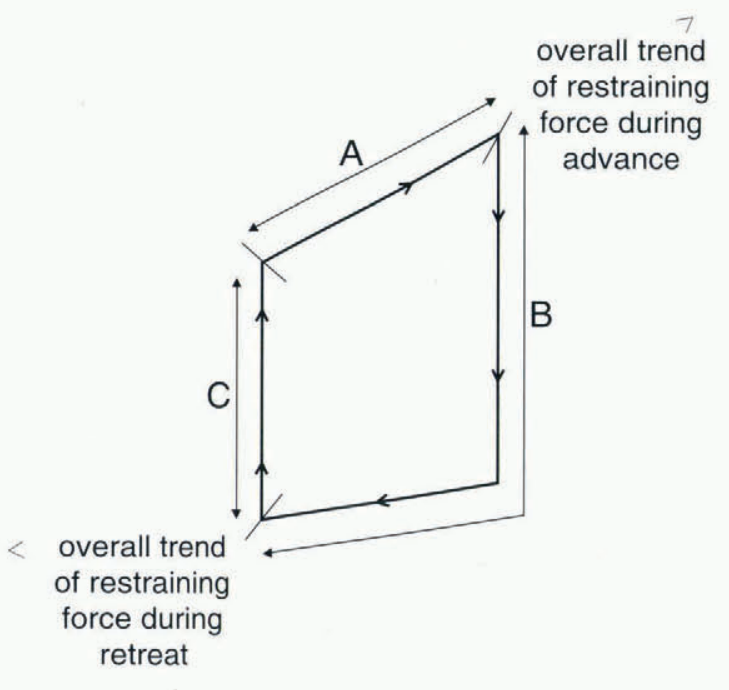

Normalized Bank Height
Fig. 13. Variation of flow rate, glacier thickness, morainal bank geometry and calving rate during a seasonal cycle of advance and retreat. (d) shows the idealized, schematic, cyclic variation in restraining forces at the terminus during stages of the cycle illustrated in $(a),(b)$ and $(c)$. Note that the linear, vertical segments of the cycle in (d) are not constrained, and that they are most likely linear, but slightly inclined to the right. For this paper, this deviation from vertical is slight enough to be disregarded. 


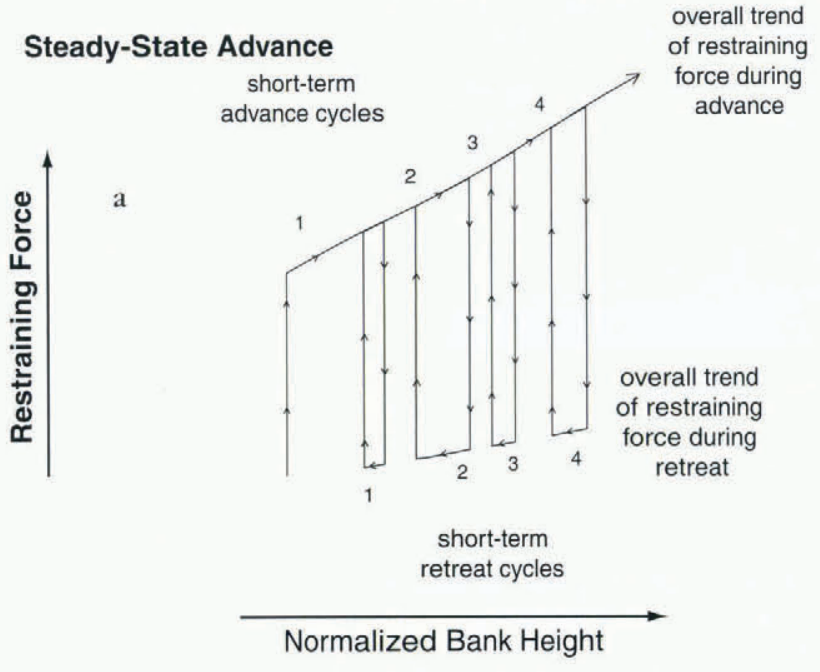

Initiation of Rapid, Sustained Retreat

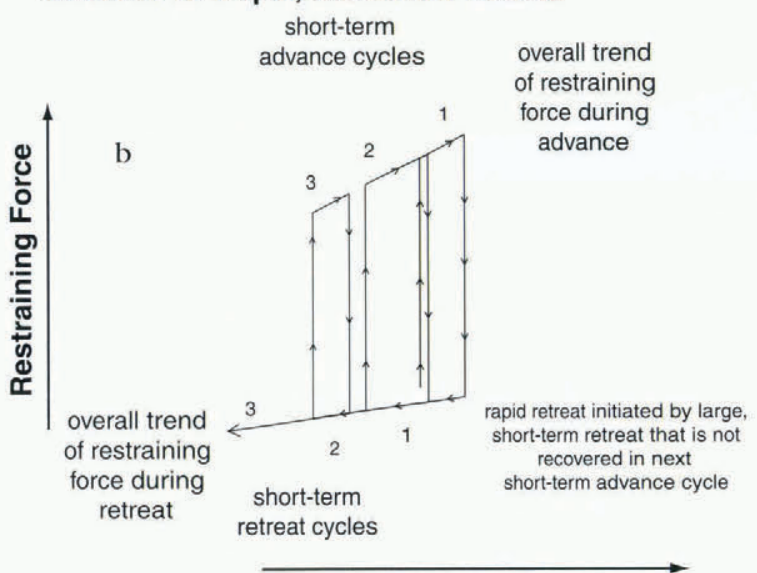

Normalized Bank Height

Fig. 14. Schematic variation in short-term restraining forces at the terminus during long-term, steady-state advance ( $a$ ) and unstable retreat $(b)$.

arise from the hydrostatic water pressure at the submerged glacier terminus, and from the support of the sediments in the bank by the ice cliff. Restraining shear forces operate when the glacier is actively pushing the morainal bank in front of it. Although the simple model we present suffers from inaccuracies in the depiction of bank and terminus geometry, and does not include aspects of sediment distribution or sedimentation rate (e.g. if the glacier flows up the back-side of the bank, resistive forces of the bank on the glacier decrease), several results are noteworthy.

During advance, restraining forces increase at an increasing rate. Glacial advance is thus a stable process, governed by a negative feedback, eventually leading to a complete cessation of advance. During retreat, restraining forces decrease at a decreasing rate. This behavior suggests retreat is a positive feedback, and an inherently unstable process. The instability in short-term seasonal advanceretreat cycle is moderated by the presence of a morainal bank, which supplies a significant restraining force to the glacier terminus. Sustained, rapid retreat can only occur if bank-related restraining forces diminish below some threshold value during the retreat phase of a normal oscillatory cycle.

Our results are consistent with the idea that calving is a response to changing glacier conditions, not a cause of increased glacier retreat. The controls on glacial advance and retreat are ultimately tied to glacier flow, thinning and restraining forces at the terminus. Rapid flow leads to thinning, which in turn leads to increased calving. Flow rates are closely linked to restraining forces at the terminus, which we show are intimately associated with morainal banks.

\section{ACKNOWLEDGEMENTS}

We would like to thank C. J. van der Veen for providing us with a copy of his manuscript on tidewater calving. R.D.P. acknowledges the support of U.S. National Science Foundation grants OPP-9219048 and OPP-9223992. Reviews by R. B. Alley, C. F. Forsberg and M. J. Hambrey helped us clarify many points in this paper, and we gratefully acknowledge their constructive criticisms.

\section{REFERENGES}

Alley, R.B. 1991. Sedimentary processes may cause fluctuations of tidewater glaciers. Ann. Glaciol., 15, 119-124.

Brown, C. S., M. F. Meier and A. Post. 1982. Calving speed of Alaska tidewater glaciers, with application to Columbia Glacier. U.S. Geol. Surv. Prof. Pap. 1258-C.

Cai, J., R. D. Powell, E. A. Cowan and P. R. Carlson. In press. Substantiating seismic reflection interpretations of temperate glacimarine sediment (Alaska) by comparison with known depositional processes and lithofacies. Mar. Geol.

Chapple, W. M. 1978. Mechanics of thin-skinned fold and thrust belts. Geol. Soc. Am. Bull., 89(8), 1189-1198.

Cowan, E. A. and R. D. Powell. 1991. Ice-proximal sediment accumulation rates in a temperate glacial fjord, southeastern Alaska. In Anderson, J. B. and G. M. Ashley, eds. Glacial marine sedimentation; paleoclimatic significance. Boulder, CO, Geological Society of America, 61-73. (GSA Special Paper 261.)

Dackombe, R.V. and V. Gardiner. 1983. Geomorphological field manual. London, Allen and Unwin.

Dahlen, F. A. 1984. Noncohesive critical Coulomb wedges: an exact solution. f. Geophys. Res., 89 (B12), 10,125-10,133.

Davis, D., J. Suppe and F. A. Dahlen. 1983. Mechanics of fold-and-thrust belts and accretionary wedges. J. Geophys. Res., 88(B2), 1153-1172.

Elliott, D. 1976. The energy balance and deformation mechanisms of thrust sheets. Philos. Trans. R. Soc. London, Ser. A, 238, 289-312.

Hubbert, M. K. and W. W. Rubey. 1959. Role of fluid pressure in mechanics of overthrust faulting. 1. Mechanics of fluid-filled porous solids and its application to overthrust faulting. Geol. Soc. Am. Bull., 70(2), 115-166.

Hughes, T. 1992. Theoretical calving rates from glaciers along ice walls grounded in water of variable depths. F. Glaciol., 38(129), 282-294.

Hunter, L. E. 1994. Grounding-line systems and glacier mass balance of modern temperate glaciers and their effect on glacier stability. (Ph.D. thesis, Northern Illinois University.)

Hunter, L. E., R. D. Powell and G.W. Smith. 1996a. Facies architecture and ground-line fan processes of morainal banks during the deglaciation of coastal Maine, U.S.A. Geol. Soc. Am. Bull., 108(8), 1022-1038.

Hunter, L. E., R. D. Powell and D. E. Lawson. 1996b. Morainal-bank sediment budgets and their influence on the stability of tidewater termini of valley glaciers entering Glacier Bay, Alaska, U.S.A. Ann. Glaciol., 22, 211-216.

Jaeger, J. C. and N. G. W. Cook. 1979. Fundamentals of rock mechanics. Third edition. London, Chapman and Hall.

Kamb, B. 1987. Glacier surge mechanism based on linked cavity configuration of the basal water conduit system. F. Geophys. Res., 92(B9), 9083-9100.

Krimmel, R. M. and B. H. Vaughn. 1987. Columbia Glacier, Alaska: changes in velocity 1977-1986. 7. Geophys. Res., 92(B9), 8961-8968.

Lambe, T.W. and R.V. Whitman. 1969. Soil mechanics. New York, etc., John Wiley and Sons.

Mayo, L. R. 1988. Advance of Hubbard Glacier and closure of Russel Fiord, Alaska - environmental effects and hazards in the Yakutat area. U.S. Geol. Surv. Circ. 1016, 4-16.

Meier, M. F. and A. Post. 1987. Fast tidewater glaciers. 7. Geophys. Res., 92(B9), 9051-9058.

Meier, M. F., L. A. Rasmussen and D. S. Miller. 1985a. Columbia Glacier in 1984: disintegration under way. U.S. Geol. Surv. Open File Rep. 85-81.

Meier, M. F., L. A. Rasmussen, R. M. Krimmel, R. W. Olsen and D. Frank. 
1985b. Photogrammetric determination of surface altitude, terminus position, and ice velocity of Columbia Glacier, Alaska. U.S. Geol. Surv. Prof. Pap. 1258-F.

Meier, M. and 9 others. 1994. Mechanical and hydrologic basis for the rapid motion of a large tidewater glacier. 1. Observations. 7. Geophys. Res., 99 (B8), 15,219-15,229.

Post, A. 1975. Preliminary hydrography and historic terminal changes of Columbia Glacier, Alaska. U.S. Geol. Surv. Hydrol. Invest. Atlas HA-559.

Powell, R. D. 1983. Glacial-marine sedimentation processes and lithofacies of temperate tidewater glaciers, Glacier Bay, Alaska. In Molnia, B. F., ed. Glacial-marine sedimentation. New York, etc., Plenum Press, 185- 232.

Powell, R. D. 1988. Processes and facies of temperate and sub-polar glaciers with tidewater fronts. Boulder, CO, Geological Society of America. (Geological Society of America Short Course Notes.)

Powell, R. D. 1991. Grounding-line systems as second-order controls on fluctuations of tidewater termini of temperate glaciers. In Anderson, J. B. and G. M. Ashley, eds. Glacial marine sedimentation; paleoclimatic significance. Boulder, CO, Geological Society of America, 75 93. (GSA Special Paper 261.

Seramur, K. C., R. D. Powell, P. R. Carlson and E. A. Cowan. 1997. Muir
Inlet morainal bank complex, Glacier Bay, S.E. Alaska. In Davies, T. A. and others, eds, Glaciated continanal margins: an atlas of acoustic images. London, Chapman and Hall, 992-93.

Van der Veen, C. J. 1996. Tidewater calving. J. Glaciol., 42(141), 375-385.

Van der Wateren, D. 1986. Structural geology and sedimentology of the Dammer Berge push moraine, FRG. In Van der Meer, J.J. M., ed. Tills and glaciotectonics. Rotterdam and Boston, A. A. Balkema, 157-182.

Van der Wateren, F. M. 1994. Processes of glaciotectonism. In Maltman, A., ed. The geological deformation of sediments. New York, Chapman and Hall, 309-335.

Zoback, M. D. and J. H. Healy. 1984. Friction, faulting and in situ stress. Annales Geophysicae, 2, 689698.

\section{APPENDIX}

The following table provides a list of terms and symbols used in this paper, including the figure or equation in which the term first appears, or is defined.
$P_{\mathrm{f}} \quad$ Hydrostatic fluid pressure

$\rho_{\mathrm{w}} \quad$ Density of water

$g \quad$ Acceleration of gravity

$d_{\max } \quad$ Maximum water depth in front of glacier

$z \quad$ Vertical position in reference frame

$F_{W} \quad$ Restraining force related to water pressure (per unit glacier width)

$D \quad$ Water depth at glacier terminus

$F_{\mathrm{BS}} \quad$ Restraining force associated with basal shearing along wedge bottom (per unit glacier width)

$x \quad$ Horizontal distance away from ice-moraine interface

$\tau_{\mathrm{b}} \quad$ Shear stress along base of wedge

$L \quad$ Length of forebank wedge in the $x$ direction

$\mu_{\mathrm{b}} \quad$ Coefficient of friction along base of forebank wedge

$\sigma_{z z}{ }^{\prime} \quad$ Vertical effective stress in wedge
Vertical stress along top of the bank due to weight of overlying water

Vertical stress in forebank wedge due solely to weight of sediment

Taper angle of forebank wedge

Vertical height (thickness) of sediment wedge at some $x$ position

Density of sediment

Shear stress along failure planes in interior of a critically tapered wedge

Friction angle for sediment comprising interior of wedge

Friction angle for sediment along wedge base

Normal stress along failure planes in internal parts of a critically tapered forebank wedge

Mịimum principal effective stress in a critically tapered wedge

Maximum principal effective stress in a critically tapered wedge

Stress misorientation angle in forebank wedge

Mean effective stress in a critically tapered wedge

Normal stress in a critically tapered wedge

Modified slope angle of Dahlen (1984)

Hubbert and Rubey (1959) fluid pressure ratio $\left(P_{\mathrm{f}} / \sigma_{z z}\right)$

Total horizontal stress (effective horizontal stress plus fluid pressure)

Horizontal normal restraining force acting on glacier terminus during advance (per unit glacier width)

Horizontal normal restraining force acting on glacier terminus during retreat (per unit glacier width)

Terminus restraining forces operating during glacier retreat (per unit glacier width)

Terminus restraining forces operating during glacier advance (per unit glacier width)
Equation (1)

Equation (1)

Equation (1)

Equation (1)

Equation (1)

Equation (2)

Equation (2)

Equation (3)

Equation (3)

Equation (3)

Equation (3)

Equation (4)

Equation (4)

Equation (5)

Equation (5)

Equation (6)

Equation (6)

Equation (8)

Fig. 7

Fig. 7

Fig. 7

Fig. 7

Fig. 7

Fig. 7

Fig. 7

Fig. 7

Fig. 7

Equation (12)

Equation (13)

Equation (15)

Equation (18)

Equation (23)

Fig. 12

Fig. 12 